\title{
MARCAS INTERATIVAS NA PRODUÇÃO ESCRITA DE ALUNOS E PROFESSORES
}

Kazue Saito Monteiro de Barros

\begin{abstract}
Resumo: Embora alguns trabalhos sobre a relação entre fala e escrita afirmem que a escrita é descontextualizada, sugerimos aqui que os autores inserem marcas interativas em seus textos de acordo com o(s) leitor(es) que têm em mente. Isso ocorre até nos textos apontados como os mais prototípi-

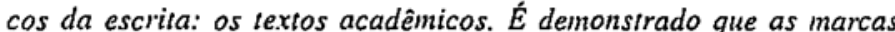
interativas sofrem variaf̧öes de acordo com uma série de caracteristicas interacionais, como a relação entre autor e leitor e o envolvimento do autor com o tópico.
\end{abstract}

Palavras-chave: marcas interativas, texto, tópico discursivo

\section{Preliminares}

O termo "marcas interativas" está sendo utilizado para designar, de forma genérica, traços que revelam aspectos dialógicos na escrita, ou seja, são estratégias de monitoraşão do texto, pelas quais o autor assinala, ao leitor que tem em mente, como deve ser interpretada a atividade de leitura. $O$ trabalho se alinha na perspectiva da relação entre fala e escrita, tomando como pressuposto que o sentido do texto, oral ou escrito, depende não só do falante/autor, mas também do ouvinte/ leitor, que utiliza as marcas interativas como pistas contextualizadoras para a construção do sentido textual. Contrariando as afirmações de alguns estudiosos da relação entre fala e escrita, as análises sugerem que, mesmo em textos acadêmicos, prototípicos da escrita, há marcas interativas que revelam um certo nível de envol-

* Universidade Federal do Rio Grande do Norte. 
vimento e contextualização. Os textos dos alunos revelam a preocupaçāo dos autores com o professor e os dos professores evidenciam pistas direcionadas ao pesquisador que coletou os dados.

É preciso enfatizar que a proposta nâo é identificar um conjunto de itens lingüísticos que possam ser listados como marcas interativas. A identificação de uma marca depende fortemente do exame das condições no momento de produção textual. Essas características são consideradas na interpretação dos resultados ou, em outras palavras, o foco dessa linha de trabalho não está na estrutura textual formal, mas no processo interativo que subjaz à produção e compreensão de textos, não s6́ orais mas também escritos.

Este trabalho se insere no âmbito do Projeto "Organização Tópica e Gêneros Textuais na Fala e na Escrita" que, por sua vez, é um dos componentes do Projeto Integrado "Fala e Escrita: características e usos II" (CNPq/UFRN/UFPE), coordenado pelo Prof. Dr. Luíz Antônio Marcuschi, da UFPE. Antes de proceder à análise aqui proposta, talvez seja necessário explicitar este contexto maior, fazendo algumas observações sobre o tema da pesquisa, seus pressupostos básicos e objetivos.

A relevância de se estudar a relaçăo entre fala e escrita vem sendo cada vez mais reconhecida, sobretudo pelas descobertas que apontam na direção de que uma melhor compreensão da fala pode facilitar a aprendizagem da escrita. Sucintamente, os estudos sobre a relação entre fala e escrita têm demonstrado que as semelhanças entre as duas modalidades são maiores do que as diferenças, que as diferenças não são estanques nem dicotômicas e que as relações podem ser melhor compreendidas se observadas no contínuo de gêneros das produções textuais (Marcuschi, 1996). Estes são os pressupostos básicos em que se ancoram todas as pesquisas que compōem o projeto integrado.

Como evidenciado no título, a pesquisa tem como foco central a organizaf̧ão tópica, tratada sob a perspectiva da relação entre fala e escrita. Concentra-se num conjunto de gêneros textuais agrupados sob o rótulo de instrucionais, referindo-se tanto à fala quanto à escrita: aulas, exposiçōes acadêmicas, textos didáticos e acadêmicos etc. Na pesquisa, os textos pedagógicos, produzidos por professores, e a produção textual dos alunos na escola são incluídos no gênero acadêmico. Considerando o contex to de sala de aula, onde a preocupação com o que está sendo dito é primordial, um dos problemas abordados é a observaçāo de estratégias facilitadoras da compreensão. Tem como objetivo geral a comparação de textos falados e escritos para a identificação de variações nos padrões recorrentes de organização tópica (do ponto de vista mais formal) e nas estratégias de monitoração tópica (do ponto de vista mais interacional). No que se refere aos aspectos téricos e metodológicos, busca estabelecer parâmetros que permitam o tratamento da organização tópica numa abordagem interacionista que dê conta tanto de textos falados como escritos.

Voltando ao caso específico deste trabalho, um conceito central é o de estrutura de participação, introduzido por Goffman (1981) para designar, na interação face a face, as diferentes formas pelas quais falante e ouvinte podem se relacionar um com o outro e com seus enunciados. Tentaremos mostrar aqui que as marcas interativas são, em parte, determinadas por mudanças no alinhamento (Goffman, 1981) entre autor-leitor e autor-texto. Apesar de estabelecidos para análises de textos orais, esses conceitos dão conta perfeitamente do fenômeno aqui estudado, o que parece ratificar a postura de que a relação entre fala e escrita pode ser trabalhada a partir das semelhanças (e não a partir da busca de diferenças polares) entre as duas modalidades.

\section{Observações sobre os dados}

Pelas razōes apresentadas no decorrer da análise, foram selecionadas para exame noventa redações de professores e alųnos, assim divididas: trinta textos de alunos, tendo como tema as festas juninas; trinta textos de professores, tendo como tema a fome; trinta textos de professores, tendo como tema a política.

As escolas estão situadas na regiāo de Encanto, zona rural do Rio Grande do Norte. Os alunos cursam o ensino fundamental: 15 estão na terceira série e têm idades entre 8 e 11 anos; os outros 15 são da quarta série, com idades entre 10 a 16 anos. As redações foram produzidas no contexto de sala de aula, a pedido do professor. Os professores escolhidos foram os que orientaram os alunos da amostra. Quanto ao grau de instruçäo, uma parte tem o primeiro grau e outra o segundo. Essa variável não é sistematicamente considerada nesse estudo, já que análises prévias demonstraram que nāo interferia nas observaçōes em questão. Os textos sobre a fome foram produzidos em setembro de 1994; de acordo com o pesquisador, alguns meses depois de uma grande seca que provocou muita fome, miséria e deserção. Todos os professores residem na área rural e são também agricultores, atividade com a qual complementam suas rendas. O pesquisador que coletou os dados é mestrando da UFRN, vive em Natal, é conhecido na região orientou os professores que colaboraram com a pesquisa. É necessário ressaltar 
- pois esse dado será relevante na interpretação dos resultados - que há, portanto, clara assimetria entre o pesquisador e os professores.

\section{Marcas interativas nas redações de alunos e professores}

Com base na observação dos dados, as marcas interativas foram divididas em três grupos, de acordo com as especificidades da estrutura da participação. Elas foram classificadas de acordo com a relação predominante que estabelecem entre: a) o autor e seu leitor presumido; b) o autor e seu texto; c) o autor e sua mensagem.

A análise que se segue se desdobra em três tempos: as marcas serão exemplificadas e comentadas, quantificadas de acordo com o tema e o autor, professor ou aluno, e o resultado será interpretado à luz das características do evento analisado: a sala de aula, procurando-se demonstrar, assim, que diferenças nas relações entre autor-leitor presumido e autor-texto são responsáveis por variaçōes no uso de marcas interativas.

\subsection{Marcas interativas que estabelecem a relação direta autor-leitor presumido}

Aqui estão incluídos: a) termos de endereçamento, b) cumprimentos e c) marcas de envolvimento que se ancoram fortemente em conhecimento partilhado entre autor e leitor. São marcas que nāo seriam esperadas em textos prototípicos da escrita, pois são características das interações face a face.

\section{Exemplo 1 (Texto 118: A, $4^{\mathrm{a}}$ série, 10 anos, 6/94):}

\section{"O São João}

As festas juninas são bastante bonitas, porque tem, danças, comidas, bebidas e tudo mais que vocês sabem.

Nestas festas eu nāo gosto de estar em casa, mas neste ano eu năo fui para nem um Iugar, porque, eu não estava muito bem de saúde e não teve nem um jeito pra mim sair de casa.

Mas mesmo assim eu gostei, porque comi bastante milho assado e algumas, pamonhas.

Eu desejo para todo mundo, que tenham as festas juninas, mais, feliz, do ano e até logo."
Nesse exemplo, com a expressão "que vocês sabem", o aluno se dirige diretamente ao professor e pesquisador, ou seja, às pessoas que encomendaram a redação. Esse uso tem a ver com a postura comum na escola que "treina" o aluno para ser um mero repetidor e não gerador de informações. Também os votos "eu desejo para todo mundo, que tenham as festas juninas, mais, feliz, do ano" parecem dirigidos a seus leitores presumidos. Os cumprimentos "até logo" reforçam que tais leitores são o pesquisador e o professor: a despedida é típica de interações em que os interactantes esperam se reencontrar brevemente. Pesquisas anteriores (cf. Barros, 1986) demonstraram que, na interação em sala de aula, é comum até mesmo a supressão de cumprimentos, já que professores e alunos estão em "estado de permanente reencontro" (uma expressão comumente utilizada por analistas da conversação de linha etnometodológica).

Exemplo 2(Texto 94: A, 6/94, 9 anos):

$$
\text { “As festas juninas }
$$

As festas juninas eles são muito boa por que tem festas tem comemorasāo tem santo antônio. como eu! eu chamei algumas colegas e primos e comi milho açado mataram um bode e eu comi ele açado na fogueira eu e eu e uma amiga nos arrudiamos a fogueira eu me divertir muito eu gostei muito eu vou passar o são Pedro na casa da minha prima talvez eu acho que vai ser muito legal este mês de junho é muito divertido só se não for para os outros mas para mim é para mim hoje, amanhã, e adepois vai mudar muito porque vai ficar tudo muito alegre no são joão tem quadrilha tem milho açado tem fogueira tem um monte de coisas que eu nem seio explicar tem pamonha eu gosto muito

tial! tial."

\section{Exemplo3 (Texto 106: A, 15 anos):}

\section{"As Festas Juninas}

... teve muito fogos bombas teve a moite do Encanto que a semora falo la na novena. a festa de são joāo foi muito bom. Eu fui uma festa foi muito bom. E na noite de șāo João teve festejos tem cadilha eu sotei bonba. eu fui para um churasco e la foi muito bom.

FIN"

No exemplo 2, o cumprimento está novamente presente sob a forma da despedida "tial! tial". que assinala o desfecho do texto, similar ao "FIN" do exemplo 3. 
É comum que esses desfechos sejam enfatizados: observe-se que, no exemplo 2, a expressão está destacada e com ponto de exclamação e, no exemplo 3 , é usada em maiúsculas. Dada a fase preliminar da pesquisa, não se deve tirar conclusões precipitadas, mas esse uso de fechos prototípicos da fala ("tiau") e da escrita ("fim") no mesmo gênero textual (redação acadêmica) pode apontar para diferenças no domínio da escrita ou mesmo suscitar reflexōes sobre os processos de formulação textual na fala e na escrita. Ainda no exemplo 3, a expressão "que a semora falo la na novena" corrobora que o Ieitor presumido do aluno é a professora.

\section{Exemplo 4 (Texto 92: A, F, 3" série, 8 anos, 06/94):

$$
\text { "As festas Juninas }
$$

no dia da primeira novena eu não fui mas só que eu vi as festejas lá de cima no dia que Arlene veio foi muito bonito teve a roda de fogo fo duas rodas de fogo eu gostaria que você fosse a data que ela foi 12 foi muito bonito

Santo antônio andou por todas as casas cantando rezando Santo Antônio é o nosso Pradoeiro de toda essa comunidade quando foi no dia de Arlene minha mãe não queria ir af ela disse eu vou porque vai ser muito bonito mas também podia ter fogueira."

O aluno sabe que a professora tanto conhece Arlene quanto tem conhecimento da vinda da mesma, já que Arlene, a secretária de Educação, havia comparecido à festa do dia 12 a convite da igreja, de cujas atividades a professora participa ativamente. Assim, pode referir-se à Arlene e ao dia em que ela compareceu à festa, sem medo de não ser compreendido: "no dia que Arlene veio e quando foi no dia de Arlene". E o "você" de "eu gostaria que você fosse" refere-se, naturalmente, à professora.

\section{Exemplo 5 (Texto 16: P, 9/94):}

\section{"A fome}

A fome é uma cousa que acontece sempre ...

Outra causa da fome é a preguiça e o desmantelo, como este ano pode sair nas casas que ainda encontra gente com fome nāo tem nada nem o feijăo porque vende barato para os ricos e acabam com tudo bebendo de cachaça e nas bancas de jogos quando chegam em casa a famlia toda passando fome se desesperam e querem bater em mulher e filhos."
As marcas que estabelecem relação direta entre autor-leitor são menos comuns nos textos dos professores (mais adiante, as marcas são quantificadas), reforçando a hipótese de que se trata de falta de domínio das regras da escrita. $\mathrm{O}$ exemplo 5 é uma redação produzida por um professor que se dirige diretamente ao pesquisador via o uso do verbo no imperativo: (você) "pode sair nas casas".

\subsection{Marcas interativas que estabelecem relação entre autor-texto}

Trata-se de marcas que, embora dirigidas ao leitor presumido - daí se caracterizarem como interativas -, situam-se no tratamento do texto. Dentre as marcas dessa categoria encontradas no corpus estão: a) exemplificações, b) explicitações de point ou referente e c) marcadores conversacionais do tipo point-making devices (Ventola, 1978), isto é, aqueles que segmentam o texto em unidades menores, indicando que uma nova fase ou estágio está por começar.

Exemplo 6 (Texto 112: A, 15 anos):

$$
\text { “o sāo joāo }
$$

o são Joāo foi muito bon

para mi por que eu pasia con

meuse amigos $i$ ta bon meas amiga

faizi un fara na sira: foi so di alegria ...

bon mas ali tinha $u$ aito ... i u padi risto ...

bon mas u otro a sista era alijada ...

mais ami a quadrilha foi muito bonha

porque era muitas en fitada di muitas papeu di dar priziti ..."

Embora no exemplo 6, o texto esteja comprometido pelos problemas ortográficos, dá para perceber que se trata de uma narrativa seccionada por marcadores, assim chamando a atenção do professor que parece ser o seu leitor assumido, para a introdução de seqüências tópicas da narrativa. Afinal, na escola, a falta de compreensão por parte do professor tem como conseqüência uma nota baixa para o aluno.

Exemplo 7 (Texto 103: A, M)

"falando sobre as festas juninas": São os meis dos santos que e são joão santo Ántonio e São Pedro: todo mundo tem que comemorar 
os dias deles: com bomba com todo festejo e tem que faz: a fogueirinha: que e a comemoraçăo deles: ..."

\section{Exemplo 8 (Texto 99: A):}

"No dia 24 de Junho se comemora o São João com uma animada festa tem muitos comidas ti pigas tais como

Cangica Pamonha milho asado e canzida maria mole pé de moleque.

Em uma festa Junina ninguém fica parado, enquanto algus dançam e se divertem outros paseiam e namoram comem e fazem divesos coisas.

No dia 29 de junio tam bém e comemorado o dia de sāo Pedro. Ja estava me esquecendo do dia de Santo Antônio e nesse dia que comemorando primeira festa Junina o dia deste santo é 13 de Junho.

Essa tês festas Juninas são recebidas com muita animaçāo por todos. Vivam as festas Juninas."

Nos exemplos 7 e 8 ocorrem estratégias de organização tópica. No 7, a seqüência metatópica introduzida pelo aluno - "falando sobre festas juninas" -, organiza o que vem depois, alertando seu leitor, o professor, de que ele (o aluno) está se reportando ao tema proposto. A informação é relevante para o aluno, já que extrapolar o tema proposto pode significar avaliaçãò negativa. Essa marca bem no início do texto assinala, também, que é a vez do aluno "falar", ou seja, é como se fosse o move reativo à iniciativa do professor, pedindo que o aluno escrevesse sobre as festas juninas.

O aluno também não deve deixar "incompleto" o tema proposto pelo professor, sob pena de receber notas baixas. Daí a necessidade de incluir, mesmo no final, um tópico que deveria ter sido tratado pois, segundo ele, "já estava me esquecendo" (exemplo 8), já que festas juninas incluem São João, Santo Antônio e São Pedro.

\section{Exemplo 9 (Texto 07: P):}

$$
\text { "A política do nosso País }
$$

Posso afirmar que o caminho da política no nosso País, está muito desastroso, a forma de manipulação das Pessoas que comandam a politicagem, vai longe, enquanto a população nảo se conscientizar, essa baderneira pode se prolongar por muito e muito tempo....
A política do Brasil já deu várias provas de desconfiança com a populaçăo, aprova disso é que ninguém confia maís em ninguém, nem mesmo num plano de melhoria para todos. É problema vem se agravando cada vez mais. (plano do real) Pode ser que der certo mas só quem está confiando é quem criou. E se quem criou não levar a sério?..."

No exemplo acima parece que o autor se dá conta de que possa haver um problema de compreensão, uma vez que não explicitara que o plano de que falava, 0 "plano de melhoria para todos", era o Plano Real. Ele retoma um ponto anterior - de que a política está indo por um "caminho muito desastroso" - para completar que está cada vez pior: "é problema vem se agravando cada vez mais"). Nesse momento, o referente de plano é explicitado, ficando deslocado no conjunto do texto.

\section{Exemplo 10 (Texto 53:P,9/94):}

"A política do nosso país

A política do nosso país, está se tornando uma coisa muito séria, eles só querem saber deles mesmo, não estão nem aí para os pobres. Mais na época da eleição eles ficam se aperreando correndo atrás dos pobres para votar neles, e pobre é bicho besta mesmo, vai vota neles..

Se todo mundo fosse como eu, acho que nảo existiria corrupto no brasil. Eu só conheci um homem que dava valor aos pobres, era o Fernando Collor de Mello, este sim, era um homem que só pensava nos pobres, foi tanto que os poderosos calçaram os mandato dele, porque sabiam que se ele se candidatasse seria eleito novamente. Entăo minha opiniāo é essa. : (nâo votar em ninguém).

No segundo parágrafo há um desvio tópico (digressão) a partir do enunciado eu só conheci um homein .... quando ele começa falar de Collor, deixando o primeiro enunciado como que incompleto, pois não fica explícito o que quer dizer com se todo mundo fosse como eu. O retorno ao tópico anterior é marcado pelo entāo (um marcador de retomada) em entāo minha opiniāo é essa.:. Agora observe-se o tipo de enunciado e o ponto antes dos dois pontos: tudo indica que se tratava de um fechamento do texto, com o esso referindo-se a tudo que foi dito anteriormente, como é comum ocorrer. O autor parece duvidar se seu point seria apreendido pelo leitor decidindo, então, explicitá-lo entre parênteses."

O que ocorre tanto o exemplo 9 quanto no 10 é conseqüência das condições de formulação da escrita, na qual revisões são sempre possíveis, ou seja, a explici- 
tação da referência (exemplo 9) e o esclarecimento do point (exemplo 10) parecem acréscimos realizados a posteriori, resultantes de uma leitura do texto.

\subsection{Marcas interativas que estabelecem relação entre autor-mensagem}

Trata-se de marcas interativas utilizadas para reforçar um ponto de vista, demonstrar ênfase ou incerteza do autor em relação à sua mensagem. No corpus, as mais comuns sâo estratégias persuasivas ou de preservação da face.

\section{Exemplo 11 (Texto 56:P, 9/94, $1^{\text {" }}$ série):}

\section{"A Política}

Eu nâo gosto de política, porque existe muito cambalacho, entre todos os políticos, pois gostam de fazerem promessas e nāo cumprem.

Como aconteceu comigo que me prometeram uma ajuda e até hoje, nem se quer a cara do candidato nunca mais eu à vi.

Depois que se passa a eleição que vamos cobrar, eles falam meu tempo foi muito pouco não deu para realizar tudo que foi dito.

Desculpe, näo sei falar de políticos, nem também gosto de politico."

Relembrando as condições em que as redações dos professores foram produzidas - na escola, com tema sugerido por alguém de nível socioeconômico superior - pode-se caracterizar a situação de coleta como uma situação de teste. $O$ fato de muitos textos sobre política iniciarem com uma afirmação de rejeição ao tema como no exemplo 11 - parece uma advertência ao leitor presumido que, no caso, é o pesquisador, de que o tema não será bem desenvolvido. Com isso, insinuam que as possíveis falhas se devem ao desinteresse que têm pelo tema. O pedido de desculpas, no final do exemplo, também é um reconhecimento de que a solicitação do pesquisador não foi atendida. Dessa forma, cada autor preserva sua face negativa, resguardando-se das críticas do pesquisador, e positiva, preservando sua imagem como bom professor.

\section{Exemplo 12 (Texto 114, A):}

$$
\text { "As festas juninas }
$$

O São João comeoramos no dia 24 de junho foi muito, importantes. No São João tem muitas quadrilhas populares. sāo João tem muitas fogueiras as pessãos soltam muitos fogos fesejando as festas juninas.

- As festas juninas teremos muitas brincadeiras importantes. todos os anos na minha cidade comemoramos o São João eu acho muito importantes nós se divertimos bastantes com meus amigos, $\mathrm{e}$ amigas, minha família.

Todos os anos teremos muitas festas festejando as festas juninas e festejando também o São João que é muito bom para as pessāos diverti-se com seus amiguinhos é eu desejo que todas as festas juninas e o São João sejam di amor paz e tranqüilidade para todas as pessãos do mundo inteiro $e u$ desejo muitas coisas para as pessãos do mundo inteiro.

- Todas as festas juninas eu comemoro muito bem. No São Joāo te muitas quadrilhas bonitos fogueira, etc.

No S. João tem muitos balỏes e foguetes muitas coisas importan. tes ainda. No S. Joảo eu tenho muita emoção com as festas juninas. Nas quadrilhas populares tem homens, mulheres e crianças dançando as quadrilhas nos municípios de sua cidade."

"O São pedro comemoramos no dia 28 de junho. vai ser muito bom porque tem muitas quadrilhas populares".

Se as características no momento de produçāo textual dos professores envolve uma situação de teste, a dos alunos é ainda mais característica, já que sua condição em sala de aula é sempre a de examinado. É comum que o aluno insera em seus textos expressões avaliativas de seu próprio discurso, qualificando-o como relevante, interessante, importante. Trata-se de uma estratégia persuasiva, mas também é uma característica do discurso acadêmico em geral, já que, nesse gênero textual, espera-se sempre que o conteúdo seja relevante. É o que ocorre no exemplo 12 , no qual o aluno assinala, de forma insistente, a relevância do tópico.

\subsection{Distribuição das marcas nos três grupos de textos e observações finais}

Os resultados de ocorrência das marcas interativas pelos três conjuntos de textos podem ser vistos na tabela abaixo, onde:

$\mathrm{MI}=$ marca interativa; $\mathrm{Au}=$ autor; Leit $=$ leitor; $\mathrm{Tex}=$ texto; $\mathrm{Mens}=$ mensagem. O primeiro grupo corresponde a redaçōes de alunos sobre festas juninas (A) Festas); o segundo, a textos de professores sobre a fome (P/Fome); no terceiro, os professores escreveram sobre política (P/Polít). 
Tabela 1: Distribuição das marcas interativas

\begin{tabular}{|l|c|c|c|c|c|c|c|c|}
\hline Mis & \multicolumn{2}{|c|}{ Au/Leit } & \multicolumn{2}{c|}{ Au/Tex } & \multicolumn{2}{c|}{ Au/Mens } & \multicolumn{2}{|c|}{ Total } \\
\hline & $\mathrm{N}^{\circ}$ & $\%$ & $\mathrm{~N}^{\circ}$ & $\%$ & $\mathrm{~N}^{\circ}$ & $\%$ & $\mathrm{~N}^{\circ}$ & $\%$ \\
\hline $\mathrm{A} /$ &. & & & & & & \\
\hline Festas & 13 & 72.2 & 07 & 16.6 & 11 & 15.4 & 31 & 23.6 \\
\hline $\begin{array}{l}\text { P/ } \\
\text { Fome }\end{array}$ & 02 & 11.1 & 24 & 57.1 & 08 & 11.2 & 34 & 25.9 \\
\hline P/ & & & & & & & & \\
Polít. & 03 & 16.6 & 11 & 26.1 & 52 & 73.2 & 66 & 50.3 \\
\hline Total & 18 & 100 & 42 & 100 & 71 & 100 & 131 & 100 \\
\hline
\end{tabular}

Voltando ao point do trabalho, foi afirmado que a ocorência de marcas interativas são, em parte, determinadas por variaçōes nas relações entre autor-leitor presumido e autor-texto/mensagem. Isso pode ser demonstrado, se nos reportarmos às quatro questões que os resultados tornam mais evidentes:

a) Marcas autor-leitor: por que os textos dos alunos têm mais marcas autorleitor $(72.2 \%)$ que os textos do professor?

$\mathrm{O}$ aluno tem menor familiaridade com a escrita que o professor. Por ser mais jovem e ter poucos anos de formaçảo escolar e, portanto, ter tido menos exposição à escrita, ele domina de forma limitada as técnicas da escrita. Talvez a maior diferença que exista entre a fala e a escrita esteja relacionada às condiçōes de formulação, já que a fala envolve intercâmbio direto, com troca de falantes e a escrita não. Não se pretende dizer que os alunos de terceira e quarta séries não reconheçam essa diferença, mas que, talvez, não controlem a forma como tratar essa diferença. Na realidade, no ensino de produção textual não se espera do aluno apenas que escreva, mas que escreva segundo normas da escrita, por exemplo, com introdução, com desenvolvimento concatenado e conclusão. Indicações de fechamentos típicos como "tial! tial.", "FIN" e "até logo" parecem estratégias para não finalizar a redação de forma abrupta, o que demonstra a dificuldade do aluno em concluir seus textos nessa fase inicial de aprendizagem.

As marcas que estabelecem uma relação direta entre autor-leitor favorecem essa interaçảo, obviamente, o envolvimento interpessoal, aproximando mais os interlocutores. Como o aluno tem o professor como leitor presumido, maior envolvimento equivale a contornar a assimetria institucionalizada. Por exemplo, os cumprimentos são regras de polidez, e estabelecer um ambiente polido, mais simétrico, é vantagem para o aluno.

A ocorrência de marcas fortemente apoiadas em conhecimento partilhado pode ser ainda explicada pela assimetria em relação ao conteúdo que é veiculado na sala de aula, pois aquilo que o aluno escreve é do conhecimento do professor. Assim, o aluno pode se apoiar fortemente no conhecimento do professor, deixando muitas lacunas para serem preenchidas pelo seu leitor presumido;

b) Marcas interativas autor-texto: estão presentes em todos os três grupos de textos, mas aparecem menos no texto do aluno (16.6\%). Por que?

Acredita-se que essas marcas ocorram menos nos textos dos alunos pelo mesmo motivo citado acima: a falta de maturidade no domínio da escrita, pois inserir exemplificações, preocupar-se em evidenciar referências, apontar as unidades de um texto é reconhecer e estabelecer relevâncias, o que requer um certo nível de maturidade. Trata-se de sair da fase da verbalização textual para uma fase de tratamento do texto;

c) Ainda com relaçăo às marcas interativas autor-texto: por que os textos do professor sobre fome têm mais marcas $(57.1 \%)$ que seus textos sobre política (26.1\%)?;

d) Nas marcas autor-mensagem: por que, nos textos do professor sobre política, há tantas marcas desse tipo (73.2\% versus $11.2 \%$ dos textos do professor sobre fome e $15.4 \%$ dos textos dos alunos)?

Como pode ser constatado nos exemplos, o professor tem o pesquisador como leitor presumido. O tema fome é mais familiar ao autor do que ao pesquisador, já que esse último é de classe média, vive na capital, conforme mencionado no início do trabalho. O autor assume o papel de falante principal (Bublitz, 1988), pressupondo que ele sabe algo que o leitor não sabe. Na tarefa de explicar, de esclarecer, ele utiliza marcas que tornem seu texto claro para o leitor. Num trabalho anterior, com base no mesmo corpus (Barros, 1997), foi identificado que muitas dessas marcas têm a função de garantir compreensão.

Já nos textos sobre política, a situação se inverte e o autor se reconhece como aquele que sabe menos que seu leitor, conforme deixa claro no exemplo 11 , em que pede desculpas por seu desconhecimento. 
Assim, explicamos porque existem tantas marcas que estabelecem relação entre autor-mensagem nas redaçōes dos professores sobre política, já que as estratégias de preservação da face, que ocorrem nesses textos, decorrem da ignorância do tema.

Concluindo, dependendo de como se alinham autor-leitor, autor-texto, autor-mensagem diferentes marcas interativas podem ocorrer. Isso demonstra que 0 sentido do texto escrito depende do contexto, sensível às condições no momento de produção (que devem ser consideradas nas análises). Em outras palavras, o texto escrito também deve sèr analisado numa perspectiva interacionista por permitir uma visão mais abrangente da atividade de formulação textual.

\section{Bibliografia}

BARROS, K.S.M. (1986) Aspectos da organização da interação em sala de aula. UFPE (Dissertação de mestrado).

(1998) Estrutura social, tópico e interaçāo. Marcas em redaçōes de professores e alunos. Revista da ANPOLL, n. 4, p. 97-109.

BUBLITZ, W. (1988) Supportive Fellow-Speakers and Cooperative Conversations: discourse topic and topical actions, participants role and "recipient action" in a particular type of everyday conversation. Amsterdam: John Benjamins.

GOFFMAN, E. (1981) Forms of Talk. Philadelphia: University of Pennsylvania Press.

MARCUSCHI, L.A. (1996) "Da fala para a escrita: processos de retextualizaçāo". In: $O$ tratamento da oralidade no ensino de língua, cap. 9 (no prelo).

VENTOLA, E. (1978) A Study of Conversational Strategies in English and Finnish. Universidade de Jyãskyla (Tese de doutorado).

Abstract: Although some studies on the relation between speech and writing argue that the written text is decontextualized, it is suggested that authors insert interactive markers in their texts on behalf of the readers they have in mind. Empirical evidence and arguments are offered to show that this happens even in the most prototypical written text: academic writing. It is demonstrated that these interactive markers are dependen on features associated with the interaction, such as the social relation between author and reader and the author's involvement with the topic.

Keywords: Interactive markers, text, discoursive topic

\section{O TEXTO COMO INSTRUMENTO E AAULA DE LEITURA COMO EXERCÍCIO POLÍTICO}

Ana Lygia Cunha*

Resumo: Professores de Português Instrumental da UFPA costumam receber em suas salas de aula universitários imaturos enquanto leitores. São imaluros, entre outras coisas, por näo serem capazes de ultrapassar o sentido literal do texto escrito, ou seja, por terem dificuldade em compreender o que o autor teve intenção de "fazer com seut texto". Uma proposta política do trabalho ern sala de aula fica clara na maneira de explorar o texto como recurso didático. Parece ser de consenso que a velha fórmula (entrega do texto, leitura silenciosa, discussão acerca das dificuldades de vocabulário, questôes de interpretaf̧ão) está ultrapassada. Pode-se, na leitura, ir além do que foi dito no textoaquilo que está expresso em sua superfície - $e$ o papel do professor é basicamente facilitar este processo, dando ao aluno os instrumentos necessários sem esperar que ele os peça. Este trabalho quer, a partir da discussão a respeito do desenvolvimento do leitor, apontar para uma reflexão sobre a interação professor-aluno durante a aula de leitura.

Palavras-chave: Ensino, leitura, Lingitística, Lingüística Aplicada, metodologia

Um dos preceitos da pedagogia moderna tem sido a busca do ensino que vá além da assimilação de conteúdo teórico e ouse visar à formação do cidadão cônscio de sua função social - seus direitos e deveres - e capaz de perceber de forma crítica o universo em que está inserido.

Em todas as áreas do conhecimento procura-se chegar a este ideal, principalmente, por meio da formação de futuros professores, ou seja, dos alunos dos

\footnotetext{
* Universidade Federal do Pará.
} 